\title{
DETERMINATION OF UREA USING $p$-N,N-DIMETHYLAMINOBENZALDEHYDE: SOLVENT EFFECT AND INTERFERENCE OF CHITOSAN
}

\author{
JUAN D. GIRALDO ${ }^{a}$, BERNABÉ L. RIVAS *a \\ ${ }^{a}$ Polymer Department, Faculty of Chemistry, University of Concepcion, Concepcion, Chile.
}

\begin{abstract}
An optimized spectroscopic methodology for the quantification of urea using $p$-dimethylaminobenzaldehyde (DMAB) as a derivatizing reagent is proposed to avoid changes in reproducibility caused by aging of acidic DMAB solutions, and the unintended use of different solvents. Four solvents; ethanol, methanol, 2-propanol and acetonitrile are evaluated. Acetonitrile has never been reported for the determination of urea with DMAB, and it is found to be the best medium for the quantification of urea due to its aprotic nature. The use of acetonitrile allows a more stable reaction system, which results in a faster urea quantification, less acid consumption and a more sensitive spectroscopic method. Taking into account that polymer matrices of chitosan are being used recently to develop controlled release fertilizers of urea, a complementary study is carried out to determine any interference by released chitosan macromolecules with different molecular mass and degree of deacetylation in the optimized system. The results show no appreciable changes in the sensitivity and accuracy of the methodology being other available application of this work.
\end{abstract}

Keywords:Solvent effect, Schiff bases, UV/Vis Spectroscopy, Chitosan, Controlled release fertilizers.

\section{INTRODUCTION}

Urea is currently the most popular N-fertilizer source, its consumption represents $56 \%$ of the 110.1 million of tons of nitrogen sources applied in agriculture ${ }^{1}$. Its quantification on fertilizers, soils, wastewaters, rivers, seas, blood, urine, etc. is of paramount importance ${ }^{2}$. Different institutions and organizations (e.g. FAO) have been concerned about this and have published several methods for its quantification ${ }^{3}$. Generally, these methodologies are classified into four types: chemical derivatization, color indicators, enzymatic reactions and electrochemical techniques ${ }^{4-7}$. The most common is chemical derivatization due to its easy handling and low cost ${ }^{4}$. For this methodology three spectrophotometric reagents are commonly used: monoxime diacetyl ${ }^{8}$ thiosemicarbazide and $p$-N,N-dimethylaminobenzaldehyde (Erlich reagent) ${ }^{9}$. The last of these has the advantage that reacts with urea at ambient temperature (unlike the others that need high temperatures) producing a chromogen that emits a yellow-green color that can be utilized in the quantitative and qualitative estimation of urea ${ }^{10}$.

The general reaction in scheme 1 shows the formation and structure of the chromogen, which corresponds to an imine or Schiff base that absorbs energy at $420 \mathrm{~nm}$ in the UV-Vis spectrum and obeys the Beer-Lambert law ${ }^{11}$. The reaction between DMAB and urea is initiated by the protonation of the dimethylamino group that produce a charge deficiency in the carbonyl carbon, making it susceptible to a nucleophilic attack by part of the urea ${ }^{12}$. Changes in parameters such as molar ratio between DMAB and acid, and the type of solvent to be used can alter reaction efficiency and consequently obtain non reproducible results ${ }^{3,10,11,13,14}$. For this reason, in this work we evaluates the best solvent, the optimal amount of hydrochloric acid and the possible interference of chitosan in the optimized methodology, taking into account that new controlled release fertilizers are being developed using chitosan as a polymeric matrix $^{15-17}$, and possibility the amino groups in the backbone of chitosan could react with DMAB during the determination of urea ${ }^{18}$.<smiles>CN(C)c1ccc(C=O)cc1</smiles><smiles></smiles>
Acid $\underline{ }$<smiles>NC(=O)/N=C/c1ccc(N(C=O)c2ccccc2)cc1</smiles>

Scheme 1.DMAB-urea general reaction.

\section{EXPERIMENTAL}

Materials

Chitosan of high, medium, and low molecular mass, DMAB, $\mathrm{HCl}$, urea, acetonitrile, ethanol, methanol and 2-propanol were of analytical grade and supplied by Sigma-Aldrich. A UV-Vis Cary 100 Scan Varian with glass cells of $1 \mathrm{~cm}$, a Shimadzu AUX220 analytical balance and a TKA-Lab-tower Thermo Scientific water purifier were used.

Experimental design

To establish the optimal spectroscopic methodology for the quantification of urea using $\mathrm{DMAB}$ as a colorimetric reagent, the following parameters were set: acid used $(\mathrm{HCl})$, acid and DMAB concentrations $(37 \% \mathrm{w}$ and 20 mmol L-1 respectively), system temperature $\left(20^{\circ} \mathrm{C}\right)$ and $\mathrm{DMAB}$ and urea volume solutions in the glass cell $(1800 \mu \mathrm{L}$ and $1000 \mu \mathrm{L}$, respectively). The following parameters were varied: the solvent for the DMAB (methanol, ethanol, 2-propanol, and acetonitrile), the $\mathrm{HCl}$ volume in the glass cell (5-200 $\mu \mathrm{L})$ and the molecular mass and degree of deacetylation of the chitosan in the preparation of polymer matrices.

\section{Preparation of DMAB and Urea solutions}

Four DMAB solutions $\left(20 \mathrm{mmol} \mathrm{L}^{-1}\right)$ were prepared with different solvents (ethanol, methanol, 2-propanol and acetonitrile). For the preparation of each solution, $0.3013 \mathrm{~g}$ of DMAB $(99 \% \mathrm{w})$ was weighed in a $100-\mathrm{mL}$ volumetric flask, and the volume was made up with each solvent. For urea a stock solution $\left(50 \mathrm{mmol} \mathrm{L}^{-1}\right)$ was made with ultrapure water in a $250-\mathrm{mL}$ flask. Then, 30 aliquots were pipetted to prepare standard solutions in a concentration range of $\left(0.1,0.3,0.5,0.7,0.9,3, \ldots, 49\right.$ and $\left.10 \mathrm{mmol} \mathrm{L}^{-1}\right)$ in $25-\mathrm{mL}$ flasks.

\section{Characterization of chitosan samples}

The viscosity-averaged molecular mass was determined in accordance with the methodology of Wei Wang et al. 1984, 91 and 100\% respectively.

The degree of deacetylation was established using the correlation proposed by Brugnerotto et al. 20, and the humidity and ash content were determined according to the methods proposed by Knaul J. et al. 21. The characterization results are reported in table 3 .

Preparation of chitosan matrices

Chitosan macrospheres were made in accordance with method reported by the Nishimura K. et al. ${ }^{22}$. The drops were formed using a plastic syringe with a nozzle diameter of $2 \mathrm{~mm}$.

\section{RESULTS AND DISCUSSION}

A preliminary screening (not shown) was performed in order to establish the fixed DMAB concentration and the volumes in the glass cell (see Experimental Design section for values of concentrations and volumes established). Additionally, it was also established that in order to obtain reproducible results is necessary a minimum stirring time of $10 \mathrm{~s}$ before the measure the absorbance. Shorter stirring times of the solvent/DMAB/acid/urea solution have significant variations. Differences in the absorbance at $420 \mathrm{~nm}$ 
for the same DMAB-urea reaction may have standard deviations in a range of \pm 10.37 to $\pm 0.33 \%$ for 1 to $10 \mathrm{~s}$ of previous stirring, respectively.

Preliminary studies also showed that prior preparation of solvent/DMAB/ acid stock solutions is not suitable because variations in the absorbance measurements are present. These changes are more significant with the passage of time, and in the specific case of acetonitrile/ $\mathrm{DMAB} / \mathrm{HCl}$ solutions there is no reaction with urea after 24 hours of storage. For this reason it is recommended to work in-situ.

\section{Evaluation of the $\mathrm{HCl}$ volume}

The $\mathrm{HCl}$ volume corresponding to the maximum absorbance and the minimal reaction time was determined through in-situ kinetics measurements of $1800 \mu \mathrm{L}$ of DMAB $\left(20 \mathrm{mmol} \mathrm{L}^{-1}\right)$ in each solvent, mixed with 5 to $200 \mu \mathrm{L}$ of $\mathrm{HCl}(37 \% \mathrm{w})$ and $1000 \mu \mathrm{L}$ of aqueous solution of urea $\left(10 \mathrm{mmol} \mathrm{L}^{-1}\right)$, as shown in figure 1 for acetonitrile. This optimal volume of acid suggests that an inhibition of the reaction take place when a greater quantity of acid is added. Most studies involving DMAB as a derivatizing reagent use an excess of acid regardless it may cause less sensitivity in the method ${ }^{23-25}$. In the case of the quantification of urea ( $\mathrm{pK} 0.1)$, it is expected that some molecules of urea are protonated by the acid, and the reaction with DMAB does not occur. The $\mathrm{HCl}$ volume in which maximum absorbance is obtained for all solvents is shown in table 1.

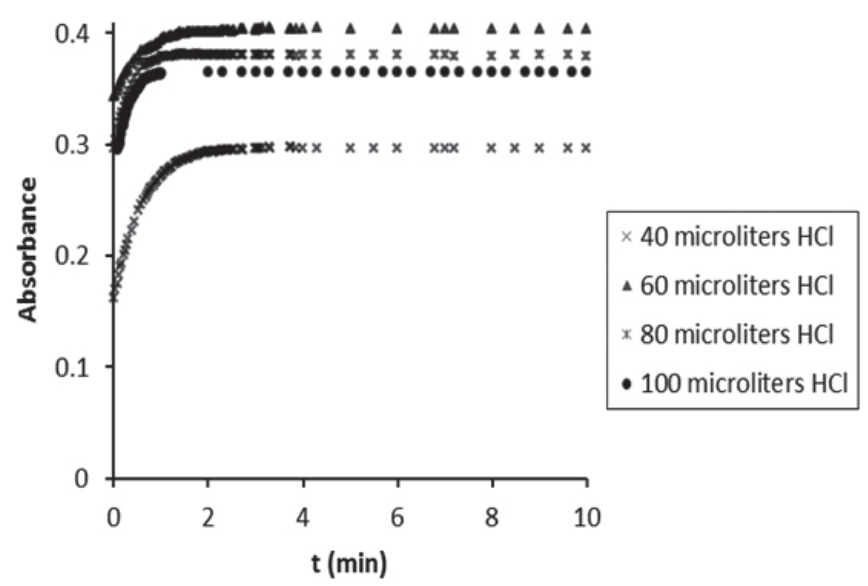

Figure 1. Evaluation of the $\mathrm{HCl}(37 \% \mathrm{~m} / \mathrm{v})$ volume in which maximum absorbance and minimum reaction time are obtained in acetonitrile (blank solution: acetonitrile/ $\mathrm{HCl} /$ water).

\section{Instability in blank solutions}

Other parameter to regard it is the color change when acid is added to DMAB solutions. Visually, a color change is observed from colorless to yellow-green without the addition of urea. This situation is confusing because the color is quite similar to that formed when DMAB reacts with urea. Relevant investigations show that the absorption spectra of DMAB in polar solvents present two bands at 242 and $352 \mathrm{~nm}$, each corresponding to different absorption process. The band at $352 \mathrm{~nm}$ corresponds to $\mathrm{n} \rightarrow \pi^{*}$ and $\pi \rightarrow \pi^{*}$ energy transitions, whereas the band at $242 \mathrm{~nm}$ corresponds to a charge transfer process $3,10,11,13,23,26-28$.

The above information suggests that in polar solvents, DMAB can have two types of electronic ground states with different structures. The first corresponds to the flat, resonant mesomeric structure (see scheme 2(a)), while the second corresponds to the charge transfer structure (see scheme 2 (b)). The last one is the result of the decoupling of nitrogen lone pair electrons and the $\pi$ cloud of the benzene ring, and it is increased when an acid is incorporated into the solvent/DMAB solution by the protonation of the dimethylamino group ${ }^{12}$.

This protonated form of DMAB is labeled as twisted internal charge transfer ground state, and can exist in molecules that have donor-acceptor groups in para-positions or two identical aromatic structures joined by a simple bond ${ }^{29}$. This structure is responsible of the color change when acid is added, due to the appearance of a phenomenon, namely, anomalous dual fluorescence effect, commonly observed in $p$-substituted benzoic compounds ${ }^{12}$.

This effect is reflected in an increase of the absorbance of the blank solutions (see in figure 2), producing an instability principally in the first minutes. This behavior is more pronounced in ethanol and methanol than in the other solvents (see figure 2 (b)), and most be taking into account when DMAB was used as a derivatizing reagent. The acetonitrile/DMAB/HCl/water system seems to be the one that more quickly stabilizes.

(a)

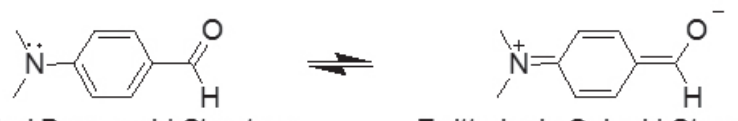

Neutral Benzenoid Structure

Zwitterionic Quinoid Structure

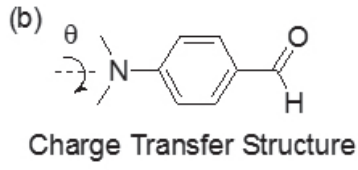

Scheme 2. (a) Flat, mesomeric resonance structures and (b) charge transfer structure of the ground states of DMAB

(a)

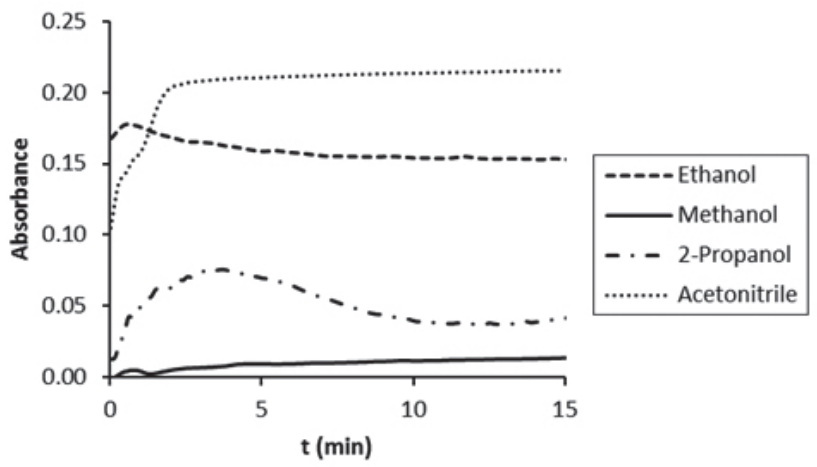

(b)

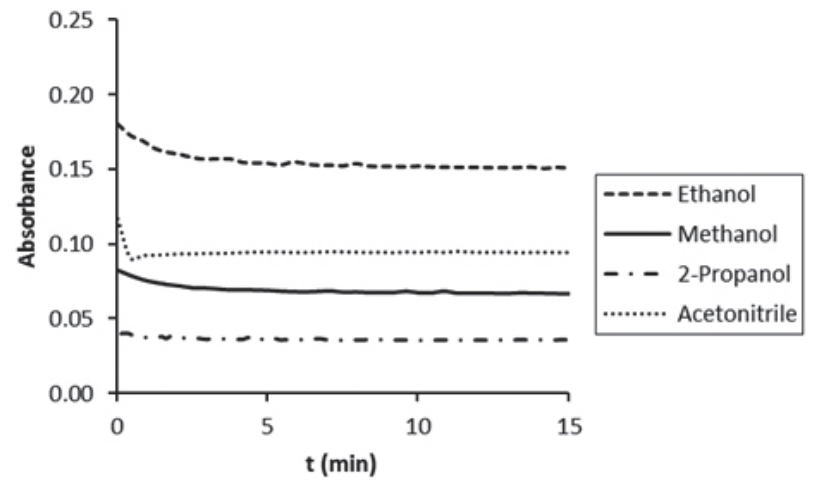

Figure 2. Changes in absorbance at $420 \mathrm{~nm}$ in the (a) solvent/DMAB system and (b) solvent/DMAB/water system after the addition of $\mathrm{HCl}$ (blank solution: solvent/ $\mathrm{HCl} /$ water)

\section{Solvent effect}

Noting that the change in the solvent affects the maximal absorbance and the time required to reach chemical equilibrium (see table 1), it is necessary to regard the nature of the solvent. With this in mind, is possible to classify solvents in terms of its specific solute/solvent interactions by taking into account the values of Dimoroth and Reichardt empirical parameter $\left(\mathrm{E}_{\mathrm{T}}^{\mathrm{N}}\right)$, relative permittivity $\left(\mathrm{e}_{\mathrm{r}}\right)$ and dipole moment $(\mu)$ shown in table 2 . On the one hand are the protic solvents, whose molecular structures contain hydrogen atoms bonded to electronegative elements and are, therefore, hydrogen-bond donors. On the other hand are the dipolar aprotic solvents which do not act as hydrogen-bond donors because their $\mathrm{C}-\mathrm{H}$ bonds are not sufficiently polarized. Solvents of the first type are characterized by relative permittivities higher than 15 and the $\mathrm{E}_{\mathrm{T}}^{\mathrm{N}}$ values between 0.5 and 1.0, indicating that these solvents are strongly polar. Solvents of the second type are characterized by relative permittivities also larger than 15 , but they have average $\mathrm{E}_{\mathrm{T}}{ }^{\mathrm{N}}$ values between 0.3 and 0.5 and sizeable dipole moments $\mathrm{m}>8.3 \times 1030 \mathrm{~cm}$. According to these ranges as is known, water, methanol, ethanol, and 2-propanol are protic solvents and acetonitrile is a dipolar aprotic solvent. The large differences 
between these types of solvents are the dipole moment and their hydrogenbonding ability ${ }^{30}$

Table 1. Critical variables for each system.

\begin{tabular}{|c|c|c|c|}
\hline Solvent & $\mathbf{t}_{\mathbf{e q}}{ }^{a}(\mathbf{m i n})$ & $\mathbf{H C l}^{b} \mathbf{( m l )}$ & $\mathbf{a b s}_{\mathbf{M a x}}{ }^{c}$ \\
\hline Methanol & $>25$ & $70 \pm \mathbf{0 . 6}$ & 0.273 \\
\hline Ethanol & 5.8 & $160 \pm \mathbf{1 . 2}$ & 0.280 \\
\hline 2-Propanol & 4.6 & $30 \pm \mathbf{0 . 6}$ & 0.110 \\
\hline Acetonitrile & 2.7 & $60 \pm \mathbf{0 . 6}$ & 0.309 \\
\hline
\end{tabular}

$2^{a}$ The time required to reach chemical equilibrium. ${ }^{b}$ The $\mathrm{HCl}$ volume corresponding to the maximum absorbance and the minimal reaction time. Maximum absorbance (blank solution: solvent/DMAB/HCl/water).

Based on the above classification, and according to the chemical nature of DMAB already mentioned, the solute/solvent systems studied here, belong to the limiting case of a dipolar solute in a polar solvent. This indicates that because the ground-state solvation in this case results largely from dipole-dipole forces, there is an oriented solvent cage around the dipolar solute molecules, which stabilizes the DMAB ground state. This situation is reflected in the bathochromic or hypsochromic shifts of the absorbance spectra, depending on the polarity of the solvent, and explained by the Franck-Condon principle ${ }^{30}$. From figure 3 (a) it seems that there is a significant bathochromic shift in the absorption spectrum when the solvent is changed to a dipolar aprotic (acetonitrile) or a protic solvent (methanol, ethanol and 2-propanol), and only small solvatochromic shifts are observed between the latter solvents.

Table 2. Physical constants in decreasing order of $\mathrm{E}_{\mathrm{T}}{ }^{\mathrm{N} a} \cdot$

\begin{tabular}{|c|c|c|c|c|}
\hline Solvent & $\mathbf{e}_{\mathbf{r}}$ & $\mathbf{m x 1 0} \mathbf{3 0}^{\mathbf{3 0}}(\mathbf{C m})$ & $\mathbf{p K}_{\mathbf{a}}$ & $\mathbf{E}_{\mathbf{T}}^{\mathbf{N}}$ \\
\hline Water & 78.36 & 6.20 & 15.74 & 1.00 \\
\hline Methanol & 32.66 & 5.90 & 15.50 & 0.76 \\
\hline Ethanol & 24.55 & 5.80 & 16.00 & 0.65 \\
\hline 2-Propanol & 19.92 & 5.50 & 17.10 & 0.54 \\
\hline Acetonitrile & 35.94 & 13.0 & 25.00 & 0.46 \\
\hline
\end{tabular}

${ }^{a}$ Values taken from Solvents and Solvents Effects in Organic Chemistry, Fourth, Appendix A-1 ${ }^{30}$.

It can be seen from table 2 that there is an appreciable difference between the dipole moment of acetonitrile and those of the other solvents, which promotes the bathochromic shift. Therefore, the small solvatochromic shifts between methanol, ethanol and 2-propanol are because the all three have similar dipole moments. Moreover, methanol, ethanol and 2-propanol can form hydrogen bonds with the DMAB, whereby the solvatochromic shifts observed are also associated with this type of solute/solvent intermolecular interaction ${ }^{27}$ Figures 3 (b) and (c) show the solvatochromic shifts in the solvent/DMAB/HCl and solvent/DMAB/HCl/water systems.

Noting that the observed solvatochromic shifts are influenced by the nature of the solvent, the variations of the solvent/DMAB/HCl and solvent/ $\mathrm{DMAB} / \mathrm{HCl} /$ water systems are also influenced by the protic or aprotic nature of the studied solvents. According to the Bronsted-Lowry theory, the effective strength of an acid depends on the medium in which it is dissolved, due to which an increase in the acidity or basicity of the solvent alters the $\mathrm{HCl}$ strength. This results in varying extents of DMAB protonation in one or other solvent. It can be seen from figure 3 (b) that the band intensity vary from protic to aprotic solvents. This change suggests greater DMAB protonation in acetonitrile than in the other solvents. This different behavior also suggests that the acetonitrile/ $\mathrm{DMAB} / \mathrm{HCl}$ solution is more acidic than the methanol, ethanol, and 2-propanol solutions, which it is a result of lower $\mathrm{HCl}$ ionization due to the aprotic nature of the acetonitrile. In the other solutions, the DMAB faces increased proton competition by the solvents. This explains the behaviors seen in figure 2 (a) In the acetonitrile system, the proton competition only involves a weak base $\left(\mathrm{Cl}^{-}\right)$. Accordingly, figure 3 (c), shows that due to the quantitative reaction between $\mathrm{HCl}$ and water, the spectra from figure 3 (b) are leveled equally. This phenomenon is known as the levelling effect, and it is a result of the high basicity and ionizing ability of water against other solvents ${ }^{30}$

In light of these results, the nature of the solvent is reflected in the acidity of the solution, which is a key factor in urea quantification. Greater DMAB protonation increases the likelihood of reaction between a urea molecule and a DMAB molecule, which in turn translates into a more sensitive spectroscopic method. Similarly, higher DMAB protonation allows higher reaction rates and a faster spectroscopic method. Finally, poor proton competition by the solven is reflected in better system stability. Table 1 shows that when acetonitrile is used, lees time is required to reach chemical equilibrium (implying a faster method) and a high maximum absorbance is obtained (implying greater sensitivity). Also figure 2 (b) demonstrates the high stability of the system.
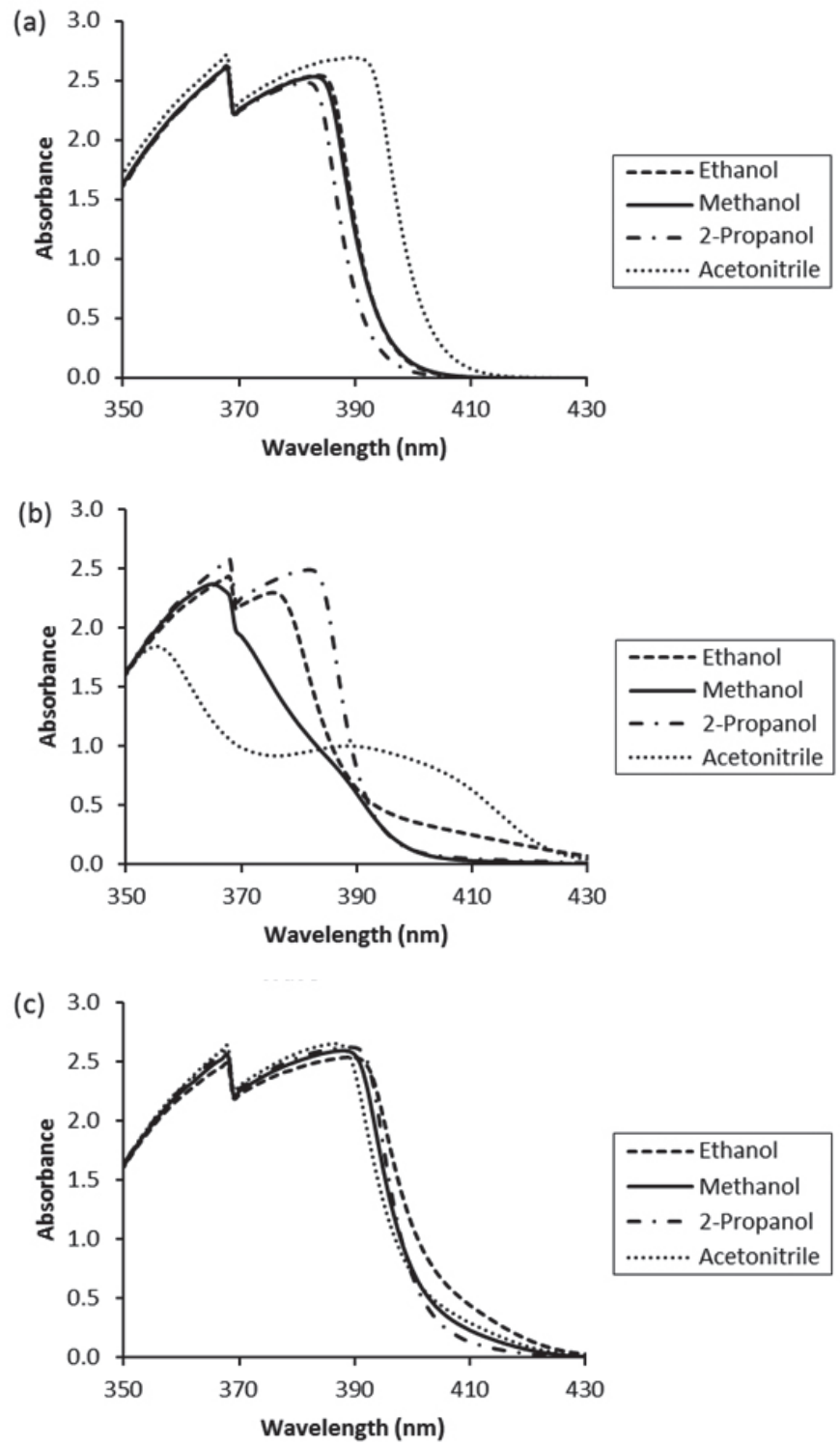

Figure 3. (a) Absorption spectra of DMAB (20 mmol L-1) in ethanol, methanol, 2-propanol and acetonitrile, (b) plus $\mathrm{HCl}$ and (c) plus $\mathrm{HCl}$ and water (COR blank solution: solvent/HCl/ water)

\section{HCl volume optimization in acetonitrile}

Established acetonitrile as the best solvent in the quantification of urea with $\mathrm{DMAB}$, the $\mathrm{HCl}(37 \% \mathrm{w})$ volume was optimized in order to obtain the acetonitrile/DMAB/HCl system with the highest absorbance, using an aqueous urea standard $\left(10 \mathrm{mmol} \mathrm{L}^{-1}\right)$ and by increasing the $\mathrm{HCl}$ volume in $2 \mu \mathrm{L}$ increments from 50 to $70 \mu \mathrm{L}$. All of the aforementioned parameter settings were maintained for this optimization. The results showed that the highest absorbance is reached at a $\mathrm{HCl}$ volume of $64 \pm 0.6 \mu \mathrm{L}$. The optimal DMAB: $\mathrm{HCl}$ molar ratio is $1: 18.18$. 


\section{Evaluation of the interference of chitosan}

Recently, chitosan matrices are being evaluated as controlled releases systems of urea ${ }^{15-17}$. To evaluate possible interference from the chitosan molecules released of these matrices, three different macrospheres without covalent or ionic crosslinking were made from three samples of chitosan with different molecular masses and deacetylation degrees (see table 3). Approximately $0.013 \mathrm{~g}$ of each macrosphere sample (see figure 4) was suspended and stirred in $20 \mathrm{~mL}$ of Milli-Q water over 24 hours, after which an aliquot was extracted from each test solution (without macrospheres) and used to make urea solutions of $10 \mathrm{mmol} \mathrm{L}^{-1}$. The three urea solutions were evaluated and contrasted with a blank solution with a urea concentration of $10 \mathrm{mmol} \mathrm{L}^{-1}$, using the acetonitrile optimized system and by triplicate. As a result of these measurements table 4 was obtained.

Table 3. Characterization of chitosan samples

\begin{tabular}{|c|c|c|c|c|}
\hline ID & $\begin{array}{c}\text { Humidity } \\
(\mathbf{\%})\end{array}$ & Ash (\%) & $\begin{array}{c}\text { Acetylation } \\
(\mathbf{\%})\end{array}$ & $\begin{array}{c}\mathbf{M}_{\mathbf{w v}} \\
(\mathbf{k D a})^{a}\end{array}$ \\
\hline Qto19 & 7.32 & 0.24 & 36.4 & 2639 \\
\hline Qto77 & 7.56 & 1.34 & 28.1 & 953 \\
\hline Qto69 & 7.86 & 0.28 & 18.1 & 659 \\
\hline
\end{tabular}

${ }^{a}$ Viscosity-averaged molecular mass.

From table 4, it is seen that the Qto19 and Qto77 solutions differed mildly from the blank solution. These differences could be errors associated with solution preparation, differences in the agitation or instrument instabilities. Conversely, the Qto69 solution differed by 3-4.5\% from the blank solution. This difference could also be explained by the previous reasons or could be caused by differences in the acetylation degree and molar mass of the chitosan used. From table 3, it is seen that the acetylation degree of Qto69 and the molar mass are less than that of the others, and suggesting less solvophobic interactions between chitosan chains and larger chain solvation by water. This allows a larger proportion of free macromolecules of chitosan in the medium. Further, a low molecular mass and a high deacetylation degree allow free macromolecules of chitosan with an extended conformation and more susceptible amino groups to react with the derivatizing reagent.

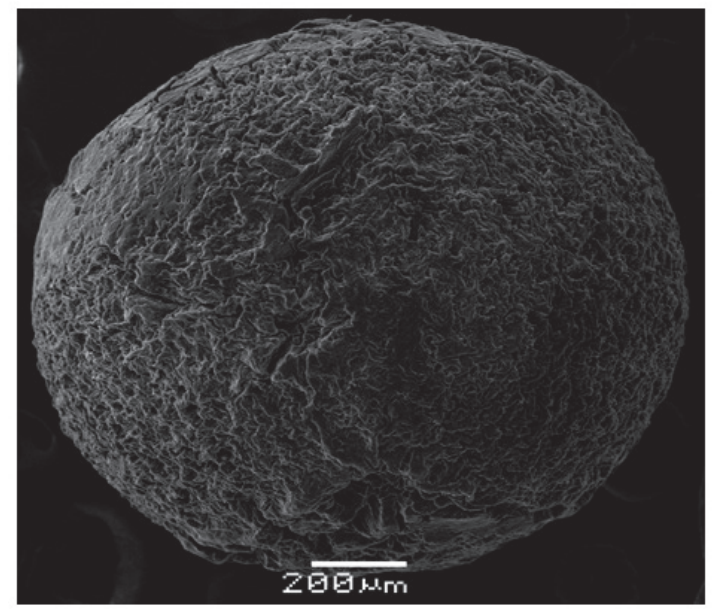

Figure 4. SEM image of a macrosphere from Qto19 sample.

Table 4. Absorbance at $420 \mathrm{~nm}$ of DMAB-urea reaction.

\begin{tabular}{|c|c|c|}
\hline Sample & $\mathbf{t}$ (min) & abs $^{a}$ \\
\hline Blank & 3 & $0.303 \pm \mathbf{0 . 0 0 4}$ \\
\hline Qto19 & 3 & $0.304 \pm \mathbf{0 . 0 0 4}$ \\
\hline Qto77 & 3 & $0.302 \pm \mathbf{0 . 0 0 4}$ \\
\hline Qto69 & 3 & $0.294 \pm \mathbf{0 . 0 0 4}$ \\
\hline
\end{tabular}

a Absorbance units of DMAB (20 mmol L-1)-urea $\left(10 \mathrm{mmol} \mathrm{L}^{-1}\right)$ at the presence of chitosan macromolecules (blank solution: acetonitrile/DMAB/ $\mathrm{HCl} /$ water).
To evaluate this possible interference, powder of Qto69 was used to obtain aqueous suspensions with different concentrations ${ }^{18}$. These suspensions were subsequently mixed with the acetonitrile optimized system and obtained their absorbance spectra by triplicate. From figure 5 , it is seen that any increment in the absorbance is observed in the range of 420 to $500 \mathrm{~nm}$, suggesting that DMAB does not react with the amino groups of the chitosan chains $5,7,26,31$.

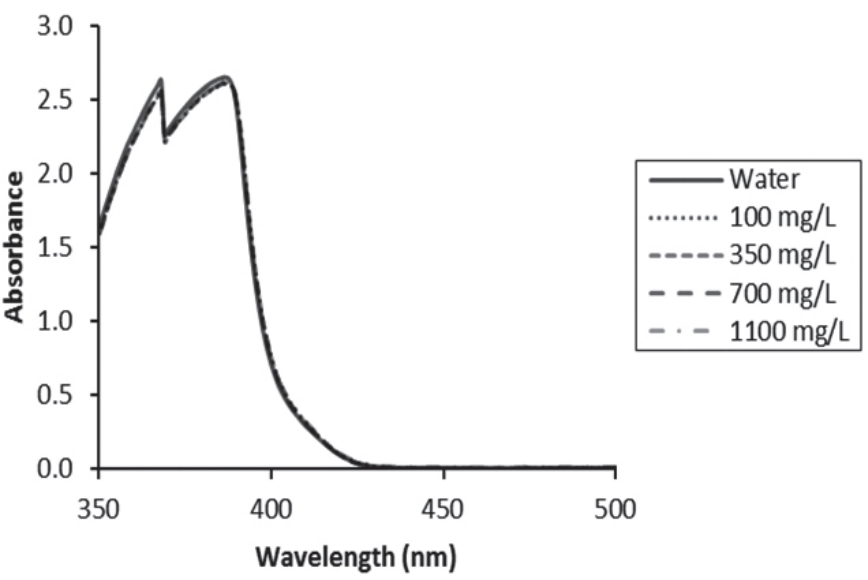

Figure 5. Absorption spectra of DMAB $\left(20 \mathrm{mmol} \mathrm{L}^{-1}\right)$ in acetonitrile/ $\mathrm{HCl}$ plus water and suspensions of Qto69 (blank solution: acetonitrile/ $\mathrm{HCl} /$ water).

\section{Characterization of the optimized methodology}

The characterization of the optimized methodology below considered its linear range, precision, limit of detection (LOD) and limit of quantification (LOQ) ${ }^{7,32}$.

Linearity $\left(\mathrm{r}^{2}\right)$ and the calibration curve obtained in a range of $0.9-39$ mmol L-1 was; 0.9999, and abs $=0.0278( \pm 0.0002) \times \mathrm{C}_{\text {Urea }}-0.005( \pm 0.004)$. The values in parentheses are the limits of the $95 \%$ confidence level intervals.

The standard deviation $\left(\mathrm{s}_{\mathrm{C}}\right)$ was used to measure the precision of the optimized methodology. Values were $\pm 0.16(\mathrm{~m}=1)$ and $\pm 0.10(\mathrm{~m}=3)$ for standards solutions $(\mathrm{m}=$ replicates $)$. The corresponding $95 \%$ confidence limits are \pm 0.336 and \pm 0.218 respectively. These statistical factors are expressed in $\mathrm{mmol} \mathrm{L}-132$

LOD and LOQ were calculated by considering the urea concentration equivalent to the analytical signal obtained by adding the blank signal to 3 (LOD) and 10 times (LOQ) the corresponding standard deviation and were 0.462 and $1.505 \mathrm{mmol} \mathrm{L}^{-1}$ respectively ${ }^{7,32}$

\section{CONCLUSIONS}

From the comparison of four different solvents for the determination of urea using DMAB as a derivatizing reagent, acetonitrile was established as the best solvent because of its dipolar aprotic nature. Established the best solvent, an optimized methodology consists of mixing in-situ (into a glass cell of 1 $\mathrm{cm}) ; 1800 \mu \mathrm{L}$ of DMAB $\left(20 \mathrm{mmol} \mathrm{L}^{-1}\right)$ in acetonitrile, $64 \mu \mathrm{L}$ of $\mathrm{HCl}(37 \% \mathrm{w})$ and $1000 \mu \mathrm{L}$ of the aqueous sample of urea. Then shake for 10 seconds and measure the absorbance at $420 \mathrm{~nm}$ after 3 minutes. Moreover, the evaluation of the interference of chitosan in the quantification of urea suggested that there is not interference by the chitosan chains. Therefore, this spectroscopy method is suitable to measure urea realized from chitosan matrices in order to develop eco-friendly-controlled-release fertilizers. On the other hand, this method has economic and environmental benefits because a considerable reduction in the consumption of DMAB, $\mathrm{HCl}$ and production of effluents are obtained.

\section{ACKNOWLEDGEMENTS}

This study was realized with funds granted by CONICYT Scholarship No 63140018.

\section{REFERENCES}

1 IFA. Fertilizer Indicators, Paris, 2013, pp. 3-4. http://www.fertilizer.org (accessed January 16 2017).

2 EPA. Toxicological Review of Urea, Washington DC., 2011, pp. 6-7. https://epa.gov/iris (accessed January 12 2017). 
3 Bibb, T. M.; Riley, C. E.; Wade, W. A.; Pearson, E. A.; Fox, M. M. Development of analytical procedures for the determination of urea manufacturing facilities. Arkansas, 1979, pp. 38 - 48.https://nepis.epa.gov (accessed June 16 2016).

4 Butler A. R., Walsh D. Trends Anal. Chem.1, 120,(1982)

5 Watt G. W., Chrisp J. D. Anal. Chem.24, 2006,(1952)

6 P. S. Francis, Lewis S. W., Lim K. F. TrAC - Trends Anal. Chem.21, $389,(2002)$

7 Oliveira H. M., Segundo M. A., Fonseca A. J. M., Cabrita A. R. J. J. Agric. Food Chem., 61, 9602,(2013)

8 Labanca R. A., Glória M. B. A.J. Agric. Food Chem.56, 5211,(2008)

9 Lambert D. F., Sherwood J. E., Francis P. S.Aust. J. Soil Res.42, 709,(2004)

10 Basova E. M., Bulanova M. A., Ivanov V. M.Moscow Univ. Chem. Bull.66, 345,(2011)

11 Hussain I., Mahmood Z., Yasmeen R., Jahangir M., Hammed R., Nasir R.J. Chem. Soc. Pakistan.24, 122.(2002)

12 Kushto G., Jagodzinski P.J. Mol. Struct.516, 215,(2000)

13 Ceriotti G., Spandrio L.Clin. Chim. Acta.8, 295.(1963)

14 Hoseney R. C, Finney K. F.Anal. Chem.36, 2145.(1964)

15 Wu L., Liu M., Rui L.Bioresour. Technol.99, 547.(2008)

16 Nadiah N., Hamid A., Mohamad N., Hing L. Y., Dimin M. F., Shaaban A.2, 893,(2013)

17 Teixeira M., Paterson W., Dunn E., Li Q., Hunter B., Goosen M.Ind. Eng. Chem. Res.29, 1205,(1990)
18 Perentena L., Gonzáles C., Celis B., Valbuena A., Colina M.Rev. Iberoam. polimeros, 16, 1,(2015)

19 Wang W., Bo S. Q., Li S. Q., Qin W.Int. J. Biol. Macromol.13, 281,(1991)

20 Brugnerotto J., Lizardi J., Goycoolea F. M., Argüelles-Monal W., Desbrières J., Rinaudo M.Polymer (Guildf).42, 3569,(2001)

21 Knaul J. Z., Kasaai M. R., BuiV. T., Creber K. A. M. Can. J. Chem.76, 1699.(1998)

22 Nishimura K., Nishimura S., Seo H., Tokura S., Azuma I.J. Biomed. Mater. Res. 20, 1359, (1986)

23 Adegoke O. A.Int. J. Pharm. Sci. Rev. Res.11, 17,(2011)

24 Adegoke O. A., Nwoke C. E.J. Iran. Chem. Soc.5, 316,(2008)

25 Adegoke O. A., Thomas O. E., Makanjuola D. M., Adewole O. O.J. Taibah Univ. Sci.8, 248,(2014)

26 Cline R. E., Fink R. M.Anal. Chem.28, 47,(1956)

27 Fathima A. A., Umadevi M., Ramakrishnan, V. J. Fluoresc. 18, 383,(2008)

28 Dobkowski J., Kirkor-Kaminska E., Koput J., Siemiarczuk A.J. Lumin.27, 339,(1982)

29 Cazeau-Dubroca C., Ait Lyazidi S., Cambou P., Peirigua A., Cazeau P., Pesquer M.J. Phys. Chem.93, 2347,(1989)

30 Reichardt C., Welton T. Solvents and Solvents Effects in Organic Chemistry, Fourth ed. , WILEY-VCH Verlag GmbH \& Co. KGaA, 2011.

31 Watt G. W., Chrisp J. D.Anal. Chem.26, 452,(1954)

32 Miller J.; Miller, J., Statistics and chemometrics for analytical chemistry, Sixth Edit ed. , Pearson Prentice Hall, 2011. 